University of Nebraska - Lincoln

DigitalCommons@University of Nebraska - Lincoln

8-2009

\title{
The leadership of emergence: A complex systems leadership theory of emergence at successive organizational levels
}

\author{
Benyamin B. Lichtenstein \\ University of Massachusetts, Boston, b.lichtenstein@umb.edu \\ Donde Ashmos Plowman \\ University of Nebraska-Lincoln, dplowman2@unl.edu
}

Follow this and additional works at: https://digitalcommons.unl.edu/managementfacpub

Part of the Management Sciences and Quantitative Methods Commons

Lichtenstein, Benyamin B. and Plowman, Donde Ashmos, "The leadership of emergence: A complex systems leadership theory of emergence at successive organizational levels" (2009). Management Department Faculty Publications. 63.

https://digitalcommons.unl.edu/managementfacpub/63

This Article is brought to you for free and open access by the Management Department at DigitalCommons@University of Nebraska - Lincoln. It has been accepted for inclusion in Management Department Faculty Publications by an authorized administrator of DigitalCommons@University of Nebraska - Lincoln. 


\title{
The leadership of emergence: A complex systems leadership theory of emergence at successive organizational levels
}

\author{
Benyamin B. Lichtenstein \\ Department of Management/Marketing, University of Massachusetts, Boston, 100 Morrissey Blvd. M-5/214, \\ Boston, MA 02215-3393, USA (Corresponding author: tel 617 287-7887, email B.Lichtenstein@umb.edu
}

\section{Donde Ashmos Plowman}

Department of Management, The University of Tennessee, 414 Stokely Management Center, Knoxville, Tennessee 37996-0545, USA

\begin{abstract}
Complexity science reframes leadership by focusing on the dynamic interactions between all individuals, explaining how those interactions can, under certain conditions, produce emergent outcomes. We develop a Leadership of Emergence using this approach, through an analysis of three empirical studies which document emergence in distinct contexts. Each of these studies identifies the same four "conditions" for emergence: the presence of a Dis-equilibrium state, Amplifying actions, Recombination/ "Self-organization", and Stabilizing feedback. From these studies we also show how these conditions can be generated through nine specific behaviors which leaders can enact, including: Disrupt existing patterns through embracing uncertainty and creating controversy, Encourage novelty by allowing experiments and supporting collective action, Provide sensemaking and sensegiving through the artful use of language and symbols, and Stabilize the system by Integrating local constraints. Finally, we suggest ways for advancing a meso-model of leadership, and show how our findings can improve complexity science applications in management.
\end{abstract}

Keywords: complexity, self-organization, non-linear interactions, case study research, leadership behaviors

\section{Introduction}

An urban church that had been declining for 50 years resisted every change effort from its leaders, but experienced identity change and internal renewal due to a small idea that emerged from interactions among its members and amplified into something radical.

Three high potential technology-oriented ventures "took off" and emerged in directions not envisioned by their founders because of unexpected triggers, including in one case an unexpected comment made by an industry expert that led to a radical transformation of the young start-up.

In the 1880s Branson, Missouri, consisted of a store and a post office, but a series of interacting events led to the emergence of a collective of 58 theatres with seating capacity twice the size of Broadway.

In the three examples above, management scientists studying organizational change documented emergence within an organization (Plowman \& Baker et al., 2007), the emergence of organizations (Lichtenstein, 2000), and emergence across organizations (Chiles, Meyer, \& Hench, 2004). Conventional notions of leadership do not fully explain how these transformations occurred, however. Whether the church, the new ventures, or in Branson, MO, the pattern was this: organizational members or lower level system participants interacted, exchanged information, and acted without coordination from a central decider, resulting in unintended changes at higher levels within and beyond the focal organization. Complexity scientists call this process emergence (Johnson, 2001; Lichtenstein et al., 2006), and our study aims to identify specific behaviors and actions that can encourage emergence in and across organizations.

1. Published as part of a festschrift and special issue of The Leadership Quarterly honoring Jerry Hunt of Texas Tech University: Meso-Modeling of Leadership: Integrating Micro- and Macro-Perspectives of Leadership 
Our examination of these three studies reveals similarities in the context of these organizations which led to the emergent outcomes; specifically each case shared the same four conditions that appear to have led to the emergence in Mission Church, the emergence of start-up companies, and emergence across the collective of theatres we now know as Branson, Missouri. Drawing on the findings from these three empirical studies, we argue that the leadership of creation and re-creation of organizational systems may be better explained by the dynamics of emergence than by specific directives from managers who are designated as organizational leaders. In this vein, we propose a leadership of emergence: Rather than leadership "being in" a specific manager or $\mathrm{CEO}$, it emerges throughout the organization as positive influence, novelty, and outcomes.

This is not to say that formal leaders don't or shouldn't play a role in bringing about change. Indeed, we show nine specific leadership behaviors that foster the contextual conditions needed for emergence. We also suggest that these can be enacted by managers and line employees at all levels of the organization, through every interaction across the organization. Overall, we present a conceptual model for the leadership of emergence, wherein the nine behaviors trigger four contextual conditions that can lead to the creation of new order in the system. According to data from three rich empirical studies we show that this emergent order led to an increased capacity for growth and goal achievement by transforming the nature of the organization and, in some ways, its broader environment.

We base our framework on complexity science, which provides new methodological and conceptual tools for explaining how complex adaptive systems like organizations emerge and evolve (Anderson, 1999). In particular, Complex Adaptive Systems Theory - CAST - is a framework for explaining the emergence of system-level order that arises through the interactions of the system's interdependent components (agents). The CAST view suggests that rather than being "in" someone, leadership-understood as the capacity to influence others - can be enacted within every interaction between members. In this sense, complexity's focus for leadership is literally the "space between" individuals (Lichtenstein \& Uhl-Bien et al., 2007: 5), a kind of "meso" unit of analysis that reflects the network of interactions between formal levels. The CAST view thus presents leadership as more than "coaching" or "service," each of which still assume that a person is doing the leading. Instead it is the system as a whole that instantiates emergence. Emergence in this sense occurs through the interactions across a group of agents-individual members and managers, networks, and organizations - rather than only through the behaviors of a formal manager.

Several leadership and management scholars have begun to explore this notion that leadership may not reside solely within the character or the characteristic behaviors of supervisors (Seers, 2005; Uhl-Bien et al., 2007), but rather that leadership may emerge from the interactions of all organizational members (Plowman and Duchon, 2007, 2008). This approach is reflective of calls for a meso-model of leadership (Osborn, Hunt \& Jauch, 2002) in that it accounts for both behavior and context in understanding organizational phenomenon (House, Rousseau, \& Thomas-Hunt, 1995). Specifically, our meso theory describes tangible (micro) behaviors that can be enacted by any organizational member; these behaviors lead to four contextual (macro) conditions which have long been associated with emergence (Prigogine \& Stengers, 1984). Rather than leadership being "in" behaviors or "due to" the context, we explore the interaction dynamics between these two poles, aiming for the "space between" individual and context - the meso space (Porter \& McLaughlin, 2006). Our aim is thus to explore leadership behavior in context (House et al., 1995; Johns, 2006; Rousseau and Fried, 2001), and to gain insight on how to catalyze and enhance the creation of new order in a wide variety of organizations.

\section{Dynamics of leadership and emergence}

\subsection{Leadership as a dynamic process}

Traditional views of leadership assume that people at the top of the organization fill the leadership role, including especially the $\mathrm{CEO}$, the top management team, and the individuals with the authority to command and control the actions of others. Yet one of the key elements of leadership is influence of some kind (Yukl, 2006), and influence can occur anywhere at anytime in a system (Yukl \& Chavez, 2002; Yukl \& Falbe, 1990). Moreover, since the vast number of total interactions in an organization occur between peers rather than between formal leaders and their "followers," much of the raw influence in the system likely accrues beyond the traditional manager-follower dyadic roles. Others have identified the existence of "informal" systems of leadership (e.g. Kickul and Neuman, 2000; Wheelan and Johnston, 1996), and the notion of distributed leadership has made important inroads to the meso-modeling approach as well (e.g. Ancona \& Bresman, 2007). Over the past few years a stream of research has grown which uses complexity science to explore these interactive dynamics - behaviors and conditions associated with emergent leadership processes (e.g. Hazy et al., 2007; Marion and Uhl-Bien, 2008; Plowman et al., 2007).

The early work of Osborn et al. (2002: 798) provides a useful frame for our study: "Leadership is not only incremental influence of a boss toward subordinates, but most important it is the collective incremental influence of leaders in and around the system." Their focus "in and around the system" provides important grounding for our version of a meso-model of leadership. Whereas the vast majority of leadership theory focuses on dyadic influence-primarily in the supervisor-subordinate relationship - a meso-model of leadership connects individual behaviors with organizational contexts, thus revealing far richer dynamics of interdependence and influence. Rather than influence being directional, influence behaviors may be determined in some sense by their context (Osborn \& Hunt, 2007). Through a better understanding of this interaction between micro-behaviors and macro-context, we hope to further the meso-leadership view, in our case by examining how influence can be "mutual" and cogenerated across multiple interactions throughout the organization and its environment.

In complex systems, mutual influence across agents is necessary for survival. Agents are in constant interaction exchanging information, learning, and adapting their behavior in locally coherent ways. Every contact, every exchange of information pres- 
Table 1. Empirical studies of emergence and their four similar constructs.

\begin{tabular}{|c|c|c|c|}
\hline & $\begin{array}{l}\text { Plowman, Baker, Beck, Silansky, } \\
\text { Kulkarni, \& Travis, } 2007\end{array}$ & Lichtenstein (2000) & Chiles, Meyer \& Hench (2004) \\
\hline Theoretical focus & $\begin{array}{l}\text { "Radical Emergence" in one } \\
\text { organization: "new birth" }\end{array}$ & $\begin{array}{l}\text { Emergence (early lift-off) of } \\
\text { high-potential ventures. }\end{array}$ & $\begin{array}{l}\text { Emergence across organizations - } \\
\text { creation of "agglomeration" }\end{array}$ \\
\hline Longitudinal data & 10 years: $1995-2005$ & $\begin{array}{l}9 \text { months of weekly interviews with } \\
>50 \% \text { of all employees }(N=1000)\end{array}$ & 100 years: $1895-1995$ \\
\hline Integrative constructs & Elements in Plowman et al. & Elements in Lichtenstein, 2000 & Elements in Chiles et al. \\
\hline Dis-equilibrium state & $\begin{array}{l}\text { "Initiating Conditions... } \\
\text { Far-From-Equilibrium State"a }\end{array}$ & "Increased Organizing" & "Fluctuation Dynamics" \\
\hline Amplifying actions & "Actions Amplify Small Change" & "Tension and a Threshold of Change" & "Positive Feedback Dynamics" \\
\hline $\begin{array}{l}\text { Recombination/“" } \\
\text { Self-Organization" }\end{array}$ & “Emergent Self-Organization”b & "Emergence of a New Configuration" & "Recombination Dynamics"c \\
\hline
\end{tabular}

a. In their paper the first construct reads: "Small Change-The Initiating Conditions," and the next section reads "A Far-From-Equilibrium State Gives Way to Emergent Self-Organization." In that section they show how the small change(s) lead to a 'far-from-equilibrium' state; thus, we concatenate their process into our construct name, "Initiating Conditions ... Far-From-Equilibrium State."

b. In their paper, "Emergent Self-Organization" appears before "Actions Amplify Small Changes." Again, their second section heading reads: "A Far-From-Equilibrium State Gives Way to Emergent Self-Organization." We focus on the outcomes of the far-from-equilibrium state, namely "emergent self-organization."

c. In their paper, Recombination Dynamics appears after Stabilization Dynamics.

d. This cell does not have a direct connection to Stabilizing Feedback.

ents an opportunity for influence, which reflects one important type of leadership. While these everyday contacts may seem routine, they can be significant because each conversation builds on the last and is infused with the new information provided by the one before. In addition, some interactions can be perceived as more "meaningful" to agents, depending on the content, the norms, and their interaction.

In such complex adaptive systems, the agents in the system recognize the meaning of a given exchange, and adjust their own behavior as their response to that meaning within the system. As they do so the system changes: it is not the same system as it was before. ${ }^{2}$ That is, when an agent adjusts to new information, the agent expands his/her own behavioral repertoire, which, in effect, expands the behavioral repertoire of the system itself (Kauffman, 1993). This complexity view suggests that influence processes - including leadership - tend to occur continuously, in different degrees, throughout the system (Hazy et al., 2007; UhlBien et al., 2007). When these interactions follow a certain pattern - which we describe as four conditions or sequences - an outcome of these influences is emergence. After a brief note on our analytic methods, we describe the four contextual conditions that spark emergence, and identify the nine leadership behaviors which lead to these conditions.

\subsection{Method}

The data for our analysis comes from the three empirical studies of emergence: Chiles et al., 2004; Lichtenstein, 2000; and Plowman et al., 2007. Summaries of these studies can be found in Table 1. The constructs (in each table cell) are taken directly from the section headings that these three studies use to describe the process of emergence. Table 1 compares these three studies, and presents a set of four constructs which represent the common conditions for emergence across the three studies. We also include there a set of footnotes that explain any inconsistencies in our analysis and integration of the section headings. In the examples that follow, we have remained true to the data presented in those papers and any others that are based on the same case.

\subsection{Altering the context: system conditions for emergence across levels}

The three studies all identify and empirically confirm the same four sequential conditions for emergence which, in combination, appear to generate and explain emergent order: (1) Dis-equilibrium state; (2) Amplifying actions; (3) Recombination/Self-organization; and (4) Stabilizing feedback. Each study explains how these conditions led to their emergent outcomes, and in Table 1 we show how these four conditions or sequences correspond across the studies. We describe each of these conditions below, providing additional theoretical background in Table 2.

2. Heraclitis, the great Greek philosopher wisely said, "You cannot step in the same river twice." His student (Cratylus) said something even more profound: "You cannot step into the same river once." 
Table 2. Theoretical definitions of each condition/sequence in the leadership of emergence.

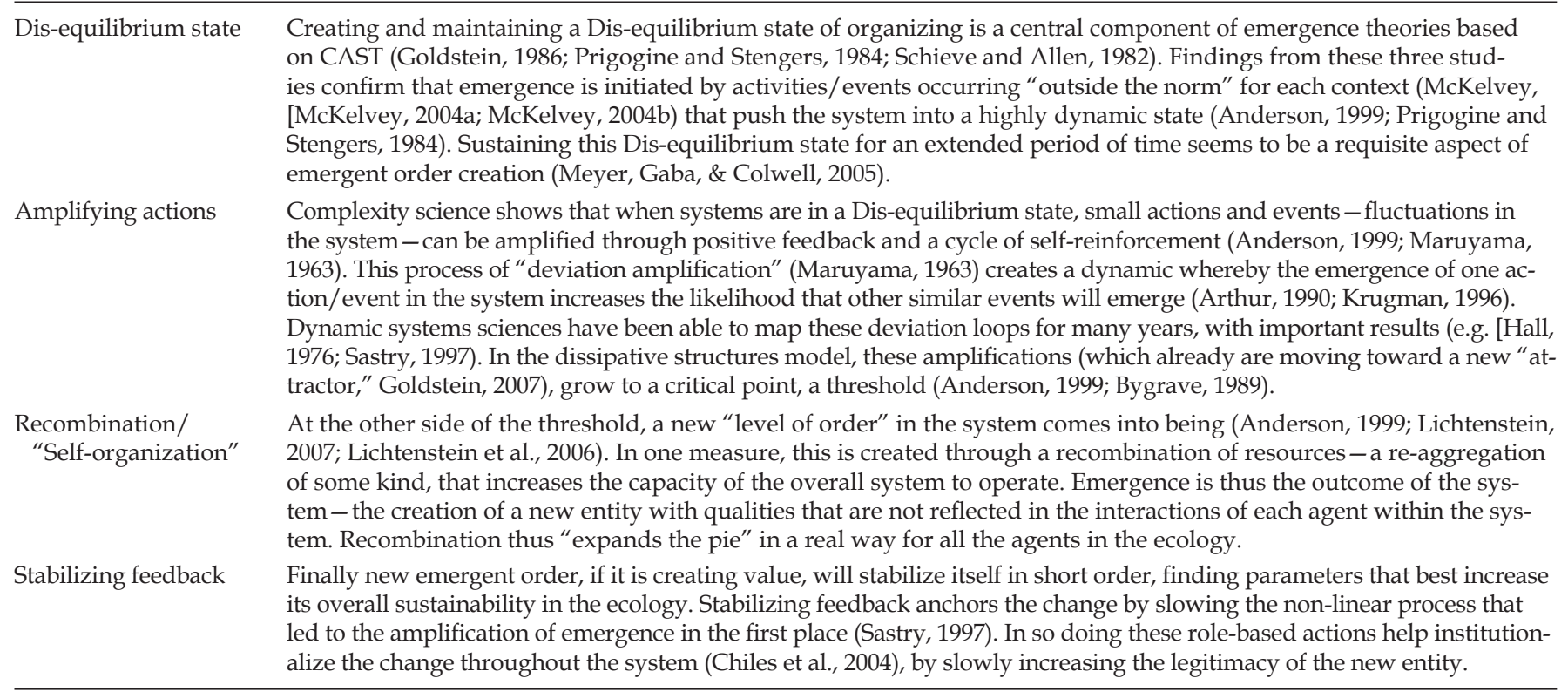

\subsubsection{Dis-equilibrium state}

Prigogine (1955) and Prigogine and Stengers (1984)) showed how chemical systems can "transform" when they shift into a state far from thermodynamic equilibrium, a state that can be imposed by infusing the system with increasing amounts of energy (e.g. heat). In social systems, Osborn et al. (2002: 822) refer to this as "Context 4: Edge of Chaos;" Maguire \& McKelvey (1999) call it the "region of complexity." Dis-equilibrium thus reflects a major disruption in system behavior - a new regime of significantly increased or decreased activity that pushes the system far beyond its existing (normally accepted) range of activity (McKelvey, 2004a; McKelvey, 2004b). ${ }^{3}$ Dis-equilibrium can be provoked by the pursuit of a new opportunity (e.g. an entrepreneurial project/venture), a threat/crisis from the environment or from within the system, or from fluctuations that alter the entire organizational system. In our three studies the authors labeled this process as far-from-equilibrium state, increased organizing, and fluctuation dynamics. These different terms all refer to the same phenomenon: a notable movement away from stability and toward dis-equilibrium, which sparks emergent change processes.

\subsubsection{Amplifying actions}

A second contextual condition for emergence identified in the three studies is Amplifying actions. When a complex adaptive system is in a Dis-equilibrium state it becomes highly sensitive to shifts in system dynamics, such that a small fluctuation in one part of the system can bring unanticipated and substantive changes to other parts of the system (Holland, 1975; Kauffman, 1993). In addition, these actions are increasingly "non-linear" due to the interdependent interconnections between system participants-individuals and/or groups. Whereas stable systems tend to buffer and diminish fluctuations, the non-linearity inherent in Dis-equilibrium states allows information to jump channels, become amplified, and move quickly through the system (Dooley, 1997). In so doing, small changes can escalate in unexpected ways. This contextual condition existed in each of the three studies of emergence, although labeled somewhat differently: amplifying actions, tension and threshold of change, positive feedback dynamics.

\subsubsection{Recombination/“Self-organization"}

The third contextual condition common to each of the three studies was Recombination/“Self-organization." At a critical threshold, when the system has reached the limit of its capacity, it can either collapse or re-organize. Collapse represents a kind of selfdisorganization, about which there is much to learn but which is not the focus of this study. The studies we examined focused more on constructive emergence through self-organization, which occurs when the agents/resources in the system re-combine in new patterns of interaction that tend to improve system functioning. Each empirical study observed this sequence, and described it as either emergent self-organization, emergence of a new configuration, or recombination dynamics.

\subsubsection{Stabilizing feedback}

The fourth contextual condition identified in the empirical studies is stabilizing feedback, that is, damping feedback that slows the amplification and keeps the emergent change from spinning the system out of control. Following the emergent changes of Mission Church and Branson, MO, both systems experienced stabilizing feedback, referred to as negative feedback and stabilization dynamics, respectively. Lichtenstein (2000) did not describe this condition in his study - see discussion for a comment on this. 


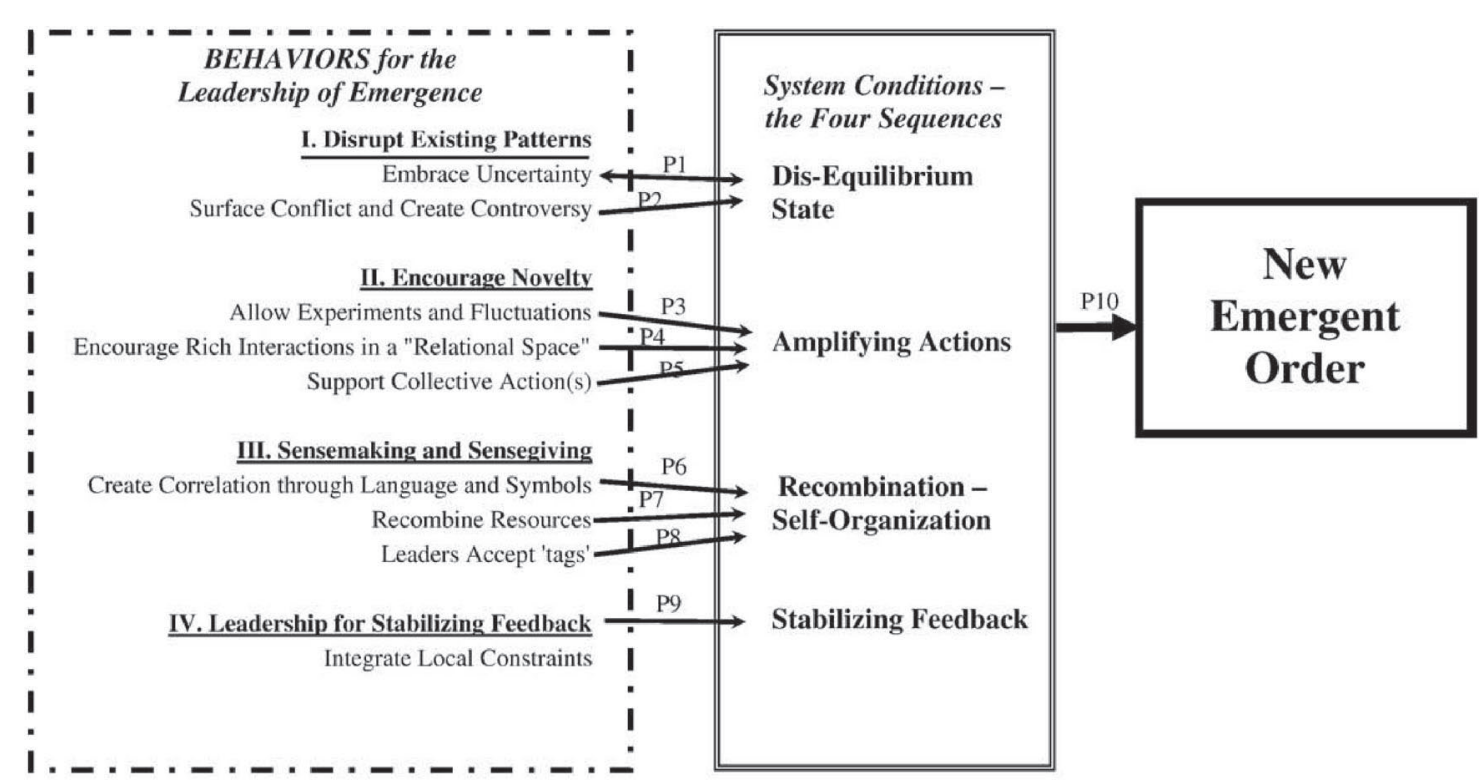

Figure 1. Behaviors that co-generate the conditions for new emergent order.

\subsubsection{Newly emergent order: outcomes}

A new emergent order occurs when there is a dramatic increase in the capacity of the system to achieve its goals (Bénard, 1901; Prigogine, 1955) by up to several orders of magnitude (Swenson, 1989, 1992). This increase in organizing capacity was evident in our studies. Mission Church, for example accomplished a significant turnaround, from major decline to a thriving institution, providing new social value to its community. The two successful ventures in Lichtenstein's sample grew many orders of magnitude in size and have remained stable for over a decade, and Branson, Missouri, is now the second-most visited place in America. ${ }^{4}$

\section{Analysis: Behaviors for enacting a leadership of emergence}

That a certain set of conditions leads to emergent order is a long-standing tenant of CAST; in fact, similar conditions were found in a series of management research papers based on Prigogine's theory of dissipative structures, including models by Leifer (1989), Smith \& Gemmill (1991), and Katz (1993). However, few complexity scholars have examined how to influence these conditions - what are the specific leadership behaviors that catalyze the four sequences and their emergent outcomes (exceptions include Goldstein, 1994; Olson and Eoyang, 2001). Uhl-Bien, Marion \& McKelvey (2007) suggested that managers who enact "enabling leadership" are more likely to produce emergent order. We build on their work by linking specific leadership behaviors to the production of each of the four system conditions. These behaviors are drawn from our three core studies; we include individual leader behaviors as well as "behaviors" or actions that can be ascribed to groups, organizations, and institutions. Our primary thesis is that these behaviors can lead to the four sequences or conditions of emergence, which in turn can generate new order in the organization/entity.

Next we present our theoretical model drawing on examples from the three cases of emergence we've been highlighting: The (re)emergence of Mission Church; the emergence of new configurations in four high-potential ventures, and the emergence of an entire community of organizations (Figure 1).

\subsection{I) Generate Dis-equilibrium by disrupting existing patterns}

At Mission Church the stage had been set for the onset of what we're calling a Dis-equilibrium state, beginning in 1995. At that point the board, desperate to stem the 50-year slide of the institution, hired their third Pastor in four years, a husband-and-wife team who were excited to work on the opportunity (turnaround) as "co-pastors." In the process a series of events unfolded that disrupted existing patterns, and the pastors accelerated the disruption by embracing uncertainty and surfacing and creating controversy in the system.

\subsubsection{Embrace uncertainty}

Throughout the early 1990s Mission Church's future became increasingly uncertain with the rapidly decreasing number of weekly church-goers, a far cry from its "silk-and-stockings" roots. Until the 1950s Mission Church had been one of the largest congregations of its time in the entire metro region, with a huge endowment that subsidized its exquisite and historic building. But the en- 
tire back wing of the Church had long ago been abandoned due to dis-use. Moreover by 1999, after four years of the leaders' tireless turnaround efforts, membership had twice again dropped sharply. Interviewees described this most recent drop as the direct response to controversial actions by the co-pastors themselves. For example, the pastors distributed a book to church members describing the characteristics of "unhealthy" churches; the authors encouraged members to "address the cause of their sickness." Open discussions of the book increased uncertainty and created some discomfort among parishioners. According to a staff member: "The (leaders) turned this world upside down, in a good way" (Plowman \& Silansky et al., 2007, p. 349).

Similar disruptions in existing patterns were evident in all three of Lichtenstein's (2000) high-potential new ventures. For example, the founder of DevelopNet had identified an opportunity to leverage their technology in an early (1996) web application that would allow real-time sales and inventory information to be accessed over the internet: "We're on the verge of becoming a \$100 million dollar company." This new and ambitious vision was based on an entirely new business model for the venture, and represented a projected revenue increase of more than $4000 \%$ for the small simulation software company. This risky commitment, which entailed using their proprietary software in an unproven way to an uncertain market in the emerging Internet field, sent the venture into a high state of dis-equilibrium.

In each of the examples we analyzed, the system (members) embraced the uncertainty they were facing, due in part to formal managers encouraging members to acknowledge and embrace the organization's precarious situation. Rather than dictate solutions, all members were encouraged to honestly assess the problems, their possible choices, and the uncertain outcomes. These behaviors, in a meso-sense, altered the context, pushing the system farther away from equilibrium. Based on this analysis we suggest:

Proposition 1: The more that leaders and members embrace uncertainty, the more likely that a Dis-equilibrium state will be initiated and/or heightened in the system. ${ }^{5}$

\subsubsection{Surface conflict and create controversy}

At Mission Church, the new co-pastors created a good deal of constructive conflict in those early years (1995-1999), welcoming homosexuals, inviting controversial speakers, and perhaps most symbolically unlocking the front doors during the week, making the church accessible to the public for the first time. Moreover, as the first changes at the Church intensified, the pastors used public media to surface and draw attention to the issues that were redefining the Church. For example, at a business community network breakfast that was scheduled to discuss the homelessness problem, one of the pastors unexpectedly arrived with twelve showered homeless people - these were some of the best known "customers" of Café Corazon, the emergent project that was the seed to the transformation at the Church (see below). This surprising move generated a series of newspaper articles and other press that amplified the issue of its marginalized citizens in the city government and beyond. As a result, these actions further destabilized the organization.

Surfacing conflict can often create more challenges, as it did during a key period at ApplySci (Lichtenstein, 2000). In order to take the last steps to finally commercialize their unique technology, a group of lab scientists and managers agreed to finally analyze a vexing and remaining obstacle to full-scale commercial production. Within just weeks of that directive, the technicians revealed the first negative results: scaled-up samples were continuously non-uniform and ineffective in ways that none of the eight researchers on the project could explain. The lab group then increased its attention on the situation, discussing it openly throughout the organization. As a result, some of the scientific assumptions underlying the technology had to be updated, limiting certain commercial options. In light of their urgent push to secure revenue through a commercialization process, this "conflict" pushed the entire venture further toward uncertainty.

When leaders or organizational members surface conflict and create controversy, they alter the conditions in which organizational members function. Goldstein (1994) described this as "difference questioning," and Pascale, Millemann and Gioja (2000: 257) refer to it as "fostering relentless discomfort." When organizations experience enough discomfort and conflict, they heighten the Dis-equilibrium state, often sparking novel ideas and options. From this we suggest:

Proposition 2: Once a system is pushed to a Dis-equilibrium state, the more that its leaders and members surface conflict and create controversy, the more likely that the system will generate novel opportunities and solutions.

\subsection{II) Amplify actions by encouraging novelty}

In all three of the studies we identified leaders and non-leaders engaging in behaviors that encouraged novelty; we describe this as Amplifying Actions. In each case, in the midst of the growing uncertainty, intensity, and fluctuations, three similar behaviors helped to amplify a seed of change, leading to newly emergent order. These actions include: Allow experiments, Encourage rich interactions, and Support collective action.

\subsubsection{Allow experiments and fluctuations}

Experiments were central to the emergence of Branson, MO. According to the authors, fluctuations were the source for "... sparking Branson's emergence as a live music theater cluster" (Chiles et al., 2004, p. 508). The first fluctuations in the 1950s and

5. One of our outstanding and helpful reviewers argued persuasively that the causal direction might well be reversed: "Given a Dis-equilibrium state, embracing uncertainty $\rightarrow$ recombination." Likewise, and even more intriguing, "Given a Dis-equilibrium state, not embracing uncertainty $\rightarrow$ collapse." 
1960s included four pioneering theaters and the first entrepreneurial tourist attraction in the area - a local folkways theme park. Then in 1983 came another unprecedented experiment supported by a local entrepreneur: Roy Clark co-founded the town's first celebrity theater, ushering in the second "new era" of growth in the region. More than a popular nightspot, Clark's theater acted as a kind of "incubator," encouraging performers from Nashville and elsewhere to experiment with their own theaters along the Branson Mall. One of the performers Clark invited was his friend and pop music icon, Andy Williams. William's decision to relocate to Branson, MO initiated a third round of "fluctuations in the 1990s [which] transformed Branson ... into a nationally known, mainstream tourist destination" (Chiles et al., 2004, p.509).

An "experiment" was also at the core of the Mission Church case: In the midst of rising uncertainty and increased controversy at the Church, a loosely affiliated group of young adults launched a unique idea: serving breakfast to the homeless people who lived in the downtown neighborhood. The pastors, who had little involvement in it, O.K.'d this "unorthodox" idea. Within a few weeks, "Café Corazon" was serving over 200 breakfasts a week and the initiative became the seed for greater and greater emergence at the Church over the next $5+$ years. The seed itself grew through a series of experiments: six months into the effort a volunteer physician spontaneously started free medical check-ups, and then recruited other doctors and services, eventually opening a medical clinic that served up to a thousand homeless people each year. Further experiments with funding and alternative programs continued to occur, resulting in unanticipated income and programs to be funded.

In both Mission Church and Branson, Missouri the behaviors of allowing and encouraging fluctuations helped create the seed of change and amplify those initial actions in unexpected ways, leading to a newly emergent order. Thus:

Proposition 3: The more that leaders and members allow experiments and fluctuations, the more likely that Amplifying Actions will be present in the system.

\subsubsection{Encourage rich interactions through a culture of "relational space"}

One quality that is characteristic of complex adaptive systems is "non-linearity," meaning that reciprocal interactions of agents create results that are often amplified and thus impossible to predict. Plowman \& Silansky et al. (2007) described this as "nonlinear interactions" by which they mean rich and meaningful interactions that can lead to unexpected and mutually supportive outcomes. Sensing the importance of this context for their turnaround efforts, the co-pastors at Mission Church initiated and facilitated many small groups within the congregation, bringing people together around shared interests, values, or life circumstances. Many of these groups started to meet weekly; over time the church was sponsoring reading groups, sports activities, dance classes, and a whole host of activities that brought members together and fostered conversations. In this way the leaders developed rich and meaningful connections among members throughout the organization. Over time this generated a kind of "relational space" in which people got to know each other quite well in small groups (Bradbury, Lichtenstein, Carroll, Powley, \& Senge, 2008). "Relational space" refers to a certain high quality of interactions, reflecting a shared context of mutual respect, trust, and psychological safety in the relationship (Bradbury and Lichtenstein, 2000; Edmondson, 1999). As predicted by complexity theory (and by managerial psychology), these rich interactions strengthened interpersonal networks, which helped amplify the changes as they emerged.

Such rich interactions were also a key to the re-emergence of ServiceCo, another high-potential new venture in Lichtenstein (2000). In response to a single critical comment by their industry mentor, the founding team decided to transform their fledgling organization through a wholesale re-design of roles and tasks there. Their goal was to identify any under-utilized intellectual capital in order to amplify the possibilities for change; they accomplished this through rich and unprecedented interactions with every employee over nearly six weeks. The founding team spent up to 2 hours with every one of the $40+$ members and managers in the firm, engaging in in-depth conversations about the possible future of the company and how each member could best contribute. These unique connections revealed competencies that had been hidden amongst the staff, leading to more novelty that helped amplify the changes at ServiceCo (Lichtenstein, 2000). Based on our observations from these studies we propose:

Proposition 4: The more that leaders and members encourage rich interactions, the more likely that Amplifying Actions will be present in the system.

\subsubsection{Support collective action}

Collective action played a significant role in the emergences at Branson, $\mathrm{MO}$, primarily through a number of influential organizational collectives around the region. By the 1920s, two such collectives were already helping draw tourists to the Ozarks by promoting the "Land of A Million Smiles;" increasing tourism was one of the critical resources that fueled Branson's astounding growth. Moreover, Branson's first theater started as a collective organization as well, back in 1955. In more recent years the Ozark Marketing Council has attracted increasing waves of tourists to the area, "channeling and accelerating" the resources necessary for emergence. Even more broadly, the collective organizing of entrepreneurs, financers and community leaders created a context for the ongoing transformations of the region (Chiles et al., 2004).

Collective action was also at the core of emergence at Mission Church, beginning with the informal group that came up with the breakfast idea during one of the co-pastor's dinner parties. The data suggest that although certain aspects of Café Corezon could be ascribed to specific individuals, it was the collective behaviors that were most influential, including the cohesion and shared vision of the entire group. For example, more than the planning and execution of the first breakfast for 70 homeless "customers" in the neighborhood, collective action was expressed in the group's decision to self-fund what became a weekly event for the entire first year of its existence. 
In all three studies, we observed an emphasis on collective action; which some call "swarm behavior." Just like social insects such as bees, termites, and ants that work without supervision yet achieve remarkable organizational accomplishments, individuals and groups in each of these studies behaved in unexpectedly connected ways. This style of chaotic collective action contributed to specific actions that amplified the initial changes. Thus, we propose:

Proposition 5: The more that leaders and members support collective action, the more likely that Amplifying Actions will be present in the system.

\subsection{III) Recombination/"Self-organization" through sensemaking and sensegiving}

In all the organizations, the next sequence of Recombination/"Self-organization" occurred through Creating correlation through symbols and language, Re-combining resources, and Accepting tags. In addition, leadership in the cases was expressed through thoughtful efforts at sensemaking (Weick, Sutcliffe \& Obstfeld, 2005) and sensegiving (Gioia \& Chittipeddi, 1991). For example, the co-pastors at Mission Church had no previous expertise working with the homeless or in social venturing. They did not create the Sunday morning breakfast idea, nor did they direct subsequent amplifications of the plan. However, as the changes emerged, the leaders began to see new possibilities for the church by making sense of what was happening, and artfully giving meaning and purpose to what was emerging. For example, the pastors began to talk about being in a ministry "with," rather than "to" the homeless; and they soon replaced the word "homeless" with the word "marginalized." Similar meaning-making occurred throughout the Branson case, and in the high potential ventures. Our analysis suggests that this sensegiving process is achieved through the next three behaviors.

\subsection{Create correlation through language and symbols}

Correlation reflects a common or shared understanding of the system (Marion \& Uhl-Bien 2001), which can be generated by specific and repeated language that helps give meaning to unfolding events, or through symbols that foster the development of a shared understanding (Plowman \& Silansky et al., 2007). A good example of correlation occurred at ServiceCo as part of the reemergence described above. Within a few days of their decision to transform ServiceCo, the top management team made several symbolic moves aimed at creating a new shared conception in the mindsets of their employees. Perhaps the most important symbol was that the founders chose to avoid all lay-offs even though one of the two projects was disbanded, instead giving new roles and responsibilities to every organizational member. Soon afterwards the office was redesigned to feature open cubicle spaces, small meeting rooms, and separate "R\&D" spaces in the office. Everyone was re-organized around the MarketServe product, as individuals from the other project were integrated into a host of new support and innovation activities. These symbolic actions helped create shared meaning about the executive team's decisions, helping all members focus their full attention on the newly emergent vision for the organization.

Similar efforts at conscious sensegiving occurred at Mission Church. Within a year, after the emergence of the Sunday morning breakfasts, the pastors at Mission Church began developing their ministry with the marginalized through Sunday sermons that focused on the many biblical examples of helping marginalized citizens. The co-pastors also initiated the creation of a new mission statement for the Church which gave more meaning to the outreach efforts by describing the Church as a place of "unconditional love and justice in action." In the process, the co-pastors' started using terms like "dignity", "respect", "justice" and "love" in their everyday interactions with congregants, thus helping to shift members" collective cognitive scripts and accepted norms toward the marginalized whom they were now serving.

Other highly symbolic actions further catalyzed the self-organization at Mission Church and are described in detail in Plowman \& Baker et al. (2007). One was the pastor's arrest, which ensued after interfering with police who were attempting to arrest one of the clients of the church's homeless shelter. Another involved the congregation's decision to remove the Chapel's nameplate, honoring a long-time leader from a century before who was a well-known KKK member. They melted the nameplate, and then turned it into a communion chalice, which they presented to their sister church, an African-American congregation in town. Symbolic actions like these, and the stories that come from them, helped distinguish and legitimize the change inside and beyond the Church. Thus we suggest:

Proposition 6: The more that leaders and members create correlation through language and through symbols, the more likely that Recombination/"Self-organization" will be initiated and expanded in the system.

\subsection{Recombine resources}

Recombining resources or capabilities was a second leadership activity that provided important benefits in the cases. For example, Chiles, Meyer \& Hench, (2004, p. 513) describe unique re-combinations of space, capital, and other key resources that drove the emergence of the Branson theater cluster:

The recombination involved in trading up to bigger, better facilities allowed theater entrepreneurs to better satisfy their patrons with an experience that was new and improved, and it freed physical capital that was recycled, refurbished, and recombined with the human and reputational capital provided by [the next] headliner [to utilize that theater], and so on in a continuous process of system-wide innovation. 
Moreover, they found that failures were also opportunities for recombination. Chiles et al. (2004: 514) quote one pioneer: “We built the theater so that if it didn't work, we could put in boat storage for the lakes. That's why we built it with no slope, with a flat floor." Like organizations designed to reconfigure themselves (Garud Kumaraswamy \& Sambamurthy 2006), self-organization was embedded into the mental models of Branson entrepreneurs, who incorporated possible reconfigurations into their initial designs. Another example occurred at Mission Church: When Café Corazon became too large for the existing building to handle, organizers requested to use the closed and dilapidated wing of the church. This reorganization allowed the Church to enlarge the ministry from a Sunday morning ministry to a homeless shelter that was open every day with space for more clinics, a large area for clothes give-aways, and the incorporation of showers and other facilities for the marginalized neighbors. Thus,

Proposition 7: The more that leaders and members recombine resources, the more likely that Self-organization will be supported throughout the system.

\subsection{Leaders are role models who accept "tags"}

Marion \& Uhl-Bien (2001) argued that leaders who enable emergence do so by becoming catalysts for actions, and by assuming the role of "tags" (Holland, 1995). A tag is an identifier for a valued set of behaviors; as such a tag directs attention to things that are important, giving meaning to actions that might otherwise go unnoticed. A change agent becomes a tag when other people see that individual as symbolizing a message that is trying to be communicated through the system. For example, the co-leaders at Mission Church, who did not initiate the small change that led to radical change, became "tags" when they focused the attention of the church community around the issues of homelessness. Later, one of the pastors decided to pursue these efforts more directly, and according to local accounts he eventually became recognized as the community's spokesman for the city's marginalized citizens. His willingness to be "tagged" as a role model in this effort helped give energy and direction to the recombination, supporting in the emergence of the project as the new core of the Church.

Such behaviors also occurred in the other studies. For example, Roy Clark and later Andy Williams made efforts to model behavior and use their high status in ways that would benefit the entire region. In particular, Chiles et al. (2004, p. 511) suggest that Clark hand picked individuals he thought would benefit from and be a benefit to the region:

"By booking stars for limited engagements and continually rotating them, Clark's theater ... introduced them to Branson's possibilities, encouraging many to set up local theaters" - a driver of the "Country Music Explosion."

Based on these examples and others we suggest:

Proposition 8: When one or a few individuals accept the role of "tag" as a symbol for an emergence process, there is a higher likelihood that Recombination/"Self-organization" will be increased in the system.

\subsection{Stabilizing feedback}

The final contextual condition enabled by the leaders in these three studies is what we call "stabilizing feedback." We identified one behavior common to these studies that enabled this condition: Integrate local constraints.

\subsubsection{Integrate local constraints}

Chiles, Meyer \& Hench (2004) identified an action that limited growth in exchange for creating a highly cohesive set of organizations. Specifically, they describe an influence behavior called: "Bransonizing," in which "locals counseled newcomers on the importance of fully reflecting local cultural values in their performances and maintaining the cultural consistency that had become central to Branson's national image" (2004, p. 512). That is, a new theater could be accepted in Branson only if it carefully honored the local culture by enacting the widely shared values of "wholesome community with traditional moral fiber and friendliness." In this way all theaters were constrained yet enabled by being more fully integrated into the local fabric of culture and beliefs that have led to Branson's success.

In the case of Mission Church the leaders encouraged self-organization while at the same time they had to apply constraints to its rapid growth. For example, Plowman \& Baker et al. (2007) report that just after the church opened a daytime shelter for the marginalized, local businesses complained about "homeless people" standing in line in the morning at the same time that nearby hotel and bank employees were arriving at work. In response to their complaints, the pastors adjusted the hours of the shelter to minimize this conflict. On the other hand, when some congregational members wanted to push the ministry towards full-scale social services, the pastors limited the growth of services into areas that they considered appropriate "ministry," thus distinguishing Mission Church from government agencies that served the poor. Overall, our analysis of these three studies suggests:

Proposition 9: The more that leaders and members integrate local constraints, the more likely that newly emergent order will be stabilized in the system.

\subsection{IV) The four conditions lead to newly emergent order}

As we've suggested throughout and as argued by the authors of the studies we examined, these four conditions appear to be necessary to the emergence of new order. (Whether or not these four are sufficient as well as necessary is beyond the scope of any study 
to date). Lichtenstein \& Jones (2004) suggested that each condition is better seen as a sequence of changes, each sequence involving a series of processes and mechanisms. Further work may illuminate how these sequences relate to each other, i.e. whether they are simultaneous, whether some precede others, etc. Even so, research in these studies and others suggests the following:

Proposition 10: The combination of the four sequences - Dis-equilibrium state, Amplifying Actions, Recombination/"Self-organization" and Stabilizing Feedback - are necessary (but not necessarily sufficient) conditions for the generation of Newly Emergent Order.

\section{Limitations, extensions, and implications}

Complexity science provides a unique theoretical scaffold that can help scholars explore a Leadership of Emergence. By taking the four identified conditions of emergence and applying them to three actual emergence events-emergence in, emergence of, and emergence across organization(s) - we were able to derive a set of leadership behaviors that are likely to encourage the creation of emerging order across multiple organizational levels. In doing this we acknowledge the limitations of our approach but also extend our work to the consideration of a meso-model of leadership and the implications of such for research.

\subsection{Limitations}

This work has numerous limitations. First, we've developed our model through a total "N" of 5 cases - Mission Church, three high-potential ventures, and Branson, MO (albeit a collective of 100 organizations). Although we are confident of our integration, we recognize that other scholars might well disagree with our choices of which studies to examine. As much as this is a limitation, it also provides an opportunity for future collaborations that can improve our work.

A related limitation is that the behaviors we mention, although shared across the sample, were idiosyncratic to their particular organizational ecologies. Through the leadership analysis of Mission Church (Plowman \& Silansky et al., 2007) these behaviors were first identified; we were then easily able to find examples of the behaviors across all the cases. However, a different set of cases or a different analysis might uncover variations and/or differences.

Equally, our approach is based on a particular view of complexity science, one which has not been central in the literature. For example, Lichtenstein (2007) identifies 14 complexity theories that have been used to explore leadership in organizations; Prigogine's dissipative structures theory is merely one of that set. Our approach, although grounded in rich qualitative data, is nevertheless biased toward this specific viewpoint. Here again, we hope scholars will expand on this work, to apply as many complexity insights as possible to the realm of leadership in particular and organization science in general.

\subsection{Connections}

In that spirit, we recognize the connections between our work and the work of others. One that bears attention is the link to Heifetz' (1994) important framework for "adaptive leadership," i.e. leadership that transforms rather than provides a technical fix. In his model, adaptive leadership starts by Identifying an Adaptive Challenge, which can only be achieved through: “... sustained periods of disequilibrium. ... Without a general sense climate of urgency - the feeling that something must change-the society [i.e. system] may do nothing until it is too late. [The key question is] how to manage sustained periods of stress" (Heifetz, 1994: 35). In a series of compelling examples Heifetz refers to several of the leadership behaviors that reflect some of the constructs we've presented, including maintaining disequilibrium (in our model, through Embracing uncertainty, Surfacing conflict, and Amplifying actions); regulating distress (i.e. Allowing experiments), Directing attention to the issues (i.e. Encouraging rich interactions, and through Sensemaking and Sensegiving), using Authority as a "Lightening Rod" of attention (i.e. through accepting "tags"), and Giving work back to the people and Protecting the Voices of Leadership in the Community (through Supporting collective action and through Self-organization). When these behaviors are used well, "the social system may mobilize to produce a new adaptation sufficient to meet the challenge" (Heifetz, 1994: 36), i.e. a new solution may emerge that transforms the adaptive capacity of the system.

Even though Heifetz is not the only leadership researcher we emulate, ${ }^{6}$ his framework reflects some key values that are embedded in the Leadership for Emergence theory. Notably, initiating emergence is hard, not only strategically but in the demands for personal and professional growth that it makes on us. In addition, the potential outcomes of emergent leadership are mostly out of our control, another challenge to anyone who considers leadership to require "being in charge." Although our paper simplifies the process to make it appear somewhat sequential and "predictable," in reality the leadership of emergence is multi-faceted, iterative, and deeply connected to each members' perceptions of the situation at hand-surely a challenge. And yet, the process can produce outcomes far beyond the ideas of any one agent.

\subsubsection{Extension 1: the leadership of emergence as a meso-model of leadership}

In one of the first major calls for this kind of research, House, Rousseau \& Thomas-Hunt $(1995$, p. 73) define meso theory and research as the simultaneous study of at least two levels of analysis - at least one concerning individual or group processes, and at least one other involving organizational processes - as well as bridging propositions that clearly link the two levels. Based on the eight distinct levels of analysis they present, our model begins to address this linkage. The leadership of emergence exam-

6. Again, thanks goes to one of our reviewers who encouraged us to make this connection. 
ines the individual and his/her dyadic (triadic, etc.) interactions, as well the actions and influences of groups on organizationwide outcomes. In addition we have outlined some possible bridging propositions which link these levels, i.e. the four conditions which, in combination, can lead to emergence.

In the process, our study has identified two "generic meso processes" described by Osborn Hunt and Jaush (2002): Isomorphisms and Discontinuities between levels in the cases. One example of an Isomorphism regards the Dis-equilibrium state: in each case the intensity of this sequence had far-reaching effects across multiple levels of the organizational ecology, affecting the decisions and behaviors of individuals, work groups, organizations, and/or collaborative partners. In a similar way, amplification effects appeared at several levels within the organizations. Overall we believe the four conditions reflect a general Isomorphism that links the different levels we've analyzed, especially through sensemaking and ambiguity.

Discontinuities are also evident, for example in the ways that the breakfast idea enacted by an informal group ran counter to the original identity of the church and its members. Another example from Lichtenstein's (2000) study is the way in which single decisions made by one organizational member (not necessarily the entrepreneur) caused dramatic and unpredictable outcomes which got played out over time in the fast-growing companies. More could be done to explore the Isomorphisms and Discontinuities in the leadership of emergence.

Secondly, we also agree with Osborn \& Hunt (2007) and Osborn et al. (2002) that by identifying the organization's particular context more can be done to link that context to leader behavior. In our cases we've suggested that these organizations are operating in "Context 4: Edge-of-Chaos" mode, in which "organizations confront dynamism, non-linearity, and unpredictability... thus promot[ing] novel behavior for the entire system that also influences the environment of the system" (Osborn et al., 2002, p. 822). Although this was evident in our cases, we also recognize that much more needs to be done to identify the specific ways that context would influence the presence, sequence, and timing of these four conditions.

The leadership of emergence offers a dynamic version of meso-level modeling (Hunt, 1991). In particular, data from our cases show that the links between individual behavior and an organization's context (the four conditions) are interdependent and reciprocal: Increases in any of the behaviors would be reflected in changes to one or more of the conditions; in turn, changes in conditions would feedback to increase or decrease those behaviors. Further, we suggest that this link is non-linear: threshold effects seem to influence the timing of emergence, as exemplified by the cycles of emergence in Branson, MO (Chiles et al., 2004) and in each of the high-potential ventures studied by Lichtenstein (2000). By tracking this non-linear and reciprocal connection between behaviors/actions $\leftarrow \rightarrow$ context, and context $\leftarrow \rightarrow$ newly emergent order, a much deeper understanding can be gained through a meso-model of leadership.

\subsubsection{Extension 2: a complexity-inspired design for a meso-level research study}

Knowing the importance of meso-models, do we as academics actually achieve them? Unfortunately, it appears that we do not: research shows that far less than $20 \%$ of published papers in management (House, Rousseau, \& Hunt, 1995) and in leadership (Porter \& McLaughlin, 2006) are multi-leveled. Why? Because, as we all learned in graduate school, longitudinal, quasi-experimental, multi-level field research is dauntingly expensive and risky, requiring hundreds of hours of effort with uncertain results that are not well supported within universities. Moreover, given the "scientific" norms of predictability (read, multiple regressions on cross-sectional data), such open-ended qualitative studies are often harder to publish, as many of us have learned.

On the other hand, good design is at the heart of good science (Edmondson \& McManus, 2007). Thus, we draw upon complexity science to suggest an "ideal study" for meso-modeling in management, and specifically for examining the leadership of emergence process.

(A) Propose the Research Question. Edmondson \& McManus' (2007)article provides useful insights that are especially important in qualitative and/or longitudinal studies. Given our goals and current research, some questions we might explore include the following: Is there an order or pattern to the progress of the four sequences, and how is this order important? When managers seek to consciously enact an approach such as ours, how are behaviors, conditions and outcomes linked?

(B) Identify the organizational partners. An "ideal" study would choose one (or two) domains and then perform a theoretical sampling (Eisenhardt, 1989) to find six to eight ventures interested in participating in the study. This case study design is appropriate given the nature of our research questions (Yin, 2003). They would need to be in an "Edge-of-Chaos" context (Osborn et al., 2002), and the partner organization's members should be willing to learn about their internal dynamics of growth and change. Ventures would ideally be less than 30 core members; data collection would follow the methods of the MIRP study by Van de Ven and his colleagues, as well as Lichtenstein's (2000) “brief question” method. ${ }^{7}$ Pursuing this further, Rousseau \& Fried (2001, p. 9) made three specific suggestions for developing “Tier 2" studies of organizational context: "Examine configurations or bundles of practices," "Focus upon events," and "Directly assess contextual effects."

(C) Examine configurations - Operationalize the venture's "Dynamic State." Following suggestions for a Dynamic States model of organizational change (Levie \& Lichtenstein, 2007), we would begin by identifying and creating baseline measures on the current "Dynamic State" of the organization. The dimensions for such an assessment have been well considered by Porter \& McLaughlin (2006, p. 563), whose model of organizational context includes these elements from which we would choose:

7. Some percent of these individuals and other key stakeholders (40\%-50\%) would agree to a periodic "brief interview" (Lichtenstein, 1998) of 10-15 min every 2-4 weeks, depending on the pace of change. (At times, well-known informants provided telephone interviews, occasionally minimizing the impact of my presence in these fast-growth companies). In the ideal, during the day that researchers are on site (e.g. bi-weekly, or monthly), they would also collect easily retrievable quantitative measures and assessments. 
(1) Structure, many dimensions of which have been measured through established scales.

(2) Processes, including core technology/task, and the primary "dominant logic" for the venture (Bettis and Prahalad, 1995; Dubinskas, 1994), including key elements of its business model (Afuah, 2004) and value chain (Senge, Smith, Kruschwitz, Laur, \& Schley, 2008).

(3) Culture/climate, again using one or two empirically established survey measures.

(4) People/composition: Through individual-level constructs/variables in the initial "baseline" data collection process, and

(5) Overall Assessment-Performance. In addition to a summary/aggregate measure, it is important to identify some agreedupon measures of performance. These should be measured regularly, perhaps on a monthly basis, using triple-bottom line techniques. In addition to the measures suggested (by a range of stakeholders), we would include a measure of "capacity" - reflecting the amount of "leverage" each unique agent (individuals, units) may have in achieving their shared goals.

(D) Focus on Events, and Directly assess context, through the periodic data collection "panels" (e.g. monthly) of interviews/visits on site:

(6) Look for and Operationalize the Four Conditions for Emergence. Over time the research team would be able to inductively develop (retrospectively?) and collect data corresponding to each of the four sequences of emergence, by (I) identifying drivers of the Dis-equilibrium state, (II) looking for Amplifying Actions, (III) capturing Recombination/“Self-organization," and (IV) evidence of stabilizing feedback.

(7) Look for Changes in State. By keeping track of the dynamic state over time, researchers should be able to identify significant shifts in that dynamic state. Based on previous research, the likelihood is that these shifts in structure, process, and tasks will correspond to a key decision point or a shared agreement that something new came-into-being in the organization. Again, unique methods have been developed which are ideal for this kind of analysis (Lichtenstein et al., 2006).

(8) Behaviors for the leadership of emergence. In our data collection and analysis we can explore some specific research questions including, who actually enacts these behaviors? What do they look like? Are some more effective than others?

\subsection{Implications for leadership and for complexity science}

An additional question that could be examined is the "bottom-up" versus "top-down" issue of leadership: To what degree does it matter if the emergent entity is started from the "bottom-up" as in the Mission Church study, versus being initiated by an entrepreneur/founding CEO who is aiming to build a successful venture. Notice in this formulation we do not place a value on whether the emergence process is initiated top-down or bottom-up, an issue that McKelvey and Lichtenstein (2007) resolved by showing that according to 300+ complexity-based computational studies, maximally only four levels (degrees) of internal structuring can ever be developed solely from the bottom-up. Top managers help in the emergence of new ideas, projects, and ventures - we simply do not yet know the right role and degree of influence that formal leaders do and perhaps should have in enacting a leadership of emergence.

A second implication of our analysis will be especially intriguing for complexity scientists. For many years complexity scholars have brought insights from the natural and artificial sciences to the field of management. In this study, however, we would argue that complexity science can gain useful insights from the organization sciences. Specifically, according to Prigogine's original experiments in far-from-equilibrium thermodynamics (Nicolis and Prigogine, 1989; Prigogine, 1955), there are actually only three conditions of emergence, not four. These three are (1) far-from-equilibrium conditions, (2) perturbations/fluctuations that get amplified near a threshold, and (3) the self-organization of structure that is composed of existing system elements. The fourth component-stabilization and negative feedback - is a management concept from sociology, which Sastry (1997) demonstrated to be a critical element in sustaining successful transformations. As noted above, Lichtenstein (2000) did not include this concept, focusing only on outcomes of emergence; this is due to his reliance on the original thermodynamic model of emergence. However, given the importance of stability and sustainability in all of these studies, we would suggest that a similar construct would be found in other dissipative structures, including those from the natural world. This fourth condition may involve the overall sustainability of the global system, i.e. how the influx of initial energy into the system is maintained over time-an issue that is only now being explored (e.g. Epstein, 2008; Senge et al., 2008). Integrating this fourth condition of stabilization after emergence should improve the relevance of these complexity models for managers.

\section{Conclusion}

In this paper we analyzed three empirical studies by complexity scholars to deepen our understanding of organizational transformation and the role of leadership in that process. In addition, we have also benefited from - and hopefully contributed tothe growing conversation about meso-models of leadership. The idea that emergence can lead systems and that leaders can foster emergence, we realize, is outside the confines of most conversations about leadership. However, if we are going to take seriously the call for leadership models that account for behavior and context at multiple levels at the same time, we believe the concept of emergence can contribute to that conversation. Finally, we are pleased to be participating in this special issue, given our appreciation for its honoree, Jerry Hunt. Jerry was one of the most active participants in the two conferences on Complexity and Leadership that were organized by Mary Uhl-Bein, Russ Marion, and the Center for Creative Leadership, among others. Dr. Hunt's efforts in expanding our view of leadership have been a huge catalyst to the work that many are now pursuing. Our hope is that this paper continues to build on Jerry's work, and contributes to a viable meso-model of leadership and management. 


\section{References}

Afuah, 2004 - A. Afuah, Business models: A strategic management approach, McGraw Hill Irwin, Boston, MA (2004).

Ancona and Bresman, 2007 - D. Ancona and H. Bresman, X-Teams: How to build teams that lead, innovate, and succeed, Harvard University Press, Cambridge, MA (2007).

Anderson, 1999 • P. Anderson, Complexity theory and organization science, Organization Science 10 (1999), pp. $216-232$.

Arthur, 1990 - W. B. Arthur, Positive feedback in the economy, Scientific American 262 (1990), pp. 92-99.

Bénard, 1901 - H. Bénard, Les tourbillons cellulaires dans une nappe liquide transportant de la chaleur par convection en régime permanent, Annales de Chimie et de Physique 23 (1901), pp. 62-114.

Bettis and Prahalad, 1995 - R. Bettis and C. K. Prahalad, The dominant logic: Retrospective and extension, Strategic Management Journal 16 (1995), pp. 5-14.

Bradbury and Lichtenstein, 2000 - H. Bradbury and B. Lichtenstein, Relationality in organizational research: Exploring the "space between, Organization Science 11 (2000), pp. 551-564.

Bradbury et al., 2008 - H. Bradbury, B. Lichtenstein, J. Carroll and P. Senge, Relational space: Key to collaborating for sustainability (2008) Working paper in Review at Management Learning.

Bygrave, 1989 • B. Bygrave, The entrepreneurship paradigm (II): Chaos and catastrophes among quantum jumps, Entrepreneurship Theory and Practice 14 (1989), pp. 7-30.

Chiles et al., 2004 • T. Chiles, A. Meyer and T. Hench, Organizational emergence: The origin and transformation of Branson, Missouri's musical theaters, Organization Science 15 (2004), pp. 499-519.

Dooley, 1997 - K. Dooley, A complex adaptive systems model of organization change, Nonlinear Dynamics, Psychology, and the Life Sciences $\mathbf{1}$ (1997), pp. 69-97.

Dubinskas, 1994 - F. Dubinskas, On the edge of chaos: A metaphor for transformative change, Journal of Management Inquiry 3 (1994), pp. 355-366.

Edmondson, 1999 - A. Edmondson, Psychological safety and learning behavior in work teams, Administrative Science Quarterly 44 (1999), pp. 350-383.

Edmondson and McManus, 2007 - A. Edmondson and S. McManus, Methodological fit in management field research, Academy of Management Review 32 (2007), pp. 1155-1179.

Eisenhardt, 1989 - K. Eisenhardt, Building theories from case-study research, Academy of Management Review 14 (1989), pp. 532-550.

Epstein, 2008 - M. Epstein, Making sustainability work, Berrett-Koehler, Greenleaf Publishing, San Francisco, CA (2008).

Gioia and Chittipeddi, 1991 - D. Gioia and K. Chittipeddi, Sensemaking and sensegiving in strategic change initiation, Strategic Management Journal 12 (1991), pp. 433-448.

Garud et al., 2006 • R Garud, A. Kumaraswamy and V. Sambamurthy, Emergent by design: Performance and transformation at Infosys Technologies, Organization Science 17 (2006), pp. 277-286.

Goldstein, 1986 • J. Goldstein, A far-from-equilibrium systems approach to resistance to change, Organizational Dynamics 15 (1) (1986), pp. 5-20.

Goldstein, 1994 • J. Goldstein, The unshackled organization, Productivity Press, Portland, OR (1994).

Goldstein, 2007 J. Goldstein, A new model for emergence and its leadership implications. In: J. Hazy, J. Goldstein and B. Lichtenstein, Editors, Complex Systems Leadership Theory, ISCE Publishing, Boston, MA (2007), pp. 61-92.

Hall, 1976 - R. Hall, A system pathology of an organization: The rise and fall of the old Saturday Evening Post, Administrative Sciences Quarterly 21 (1976), pp. 185-211.

Hazy et al., 2007 • J. Hazy, J. Goldstein and B. Lichtenstein, Complex systems leadership theory, ISCE Publishing, Boston, MA (2007).

Heifetz, 1994 - R. Heifetz, Leadership without easy answers, Harvard University Press, Cambridge, MA (1994).

Holland, 1975 • J. Holland, Adaptation in natural and artificial systems, University of Michigan Press, Ann Arbor, MI (1975).

House et al., $1995 \cdot$ R. House, D. Rousseau and M. Thomas-Hunt, The meso paradigm: A framework for the integration of micro and macro organizational behavior, Research in Organizational Behavior 17 (1995), pp. 71-115.

Hunt, 1991 • J. Hunt, Leadership: A new synthesis, Sage Publications, Newbury Park, CA (1991).

Johns, 2006 • G. Johns, The essential impact of context on organizational behavior, Academy of Management Review 31 (2006), pp. $386-408$.

Johnson, $2001 \cdot$ S. Johnson, Emergence, Scribner, New York (2001).

Katz, 1993 - J. Katz, The dynamics of organizational emergence: A contemporary group formation perspective, Entrepreneurship Theory and Practice 17 (2) (1993), pp. 97-101.

Kauffman, 1993 - S. A. Kauffman, The origins of order: Self-organization and selection in evolution, Oxford University Press, New York (1993).

Kickul and Neuman, $2000 \cdot$ J. Kickul and G. Neuman, Emergent leadership behaviors: The function of personality and cognitive ability in determining teamwork performance and KSAS, Journal of Business and Psychology 15 (1) (2000), pp. 27-51.

Krugman, 1996 • P. Krugman, The self-organizing economy, Bradford Press, Cambridge, MA (1996).

Leifer, 1989 - R. Leifer, Understanding organizational transformation using a dissipative structure model, Human Relations 42 (1989), pp. 899-916.

Levie and Lichtenstein, 2007 J. Levie and B. Lichtenstein, End of the road for life cycle theory: Toward a dynamic states model of organizational growth and change, Presented at the Academy of Management Annual Meeting; ODC Division (2007).

Lichtenstein, 1998 - B. Lichtenstein, Self-organized change in entrepreneurial ventures: A dynamic, non-linear model. Boston College/UMI, $\mathrm{PhD}$ Dissertation (1998).

Lichtenstein, 2000 - B. Lichtenstein, Self-organized transitions: A pattern amid the 'chaos' of transformative change, Academy of Management Executive 14 (2000), pp. 128-141.

Lichtenstein, 2007 B. Lichtenstein, A matrix of complexity for leadership. In: J. Hazy, J. Goldstein and B. Lichtenstein, Editors, Complex systems leadership theory, ISCE Press, Boston, MA (2007), pp. 285-304.

Lichtenstein and Jones, 2004 - B. Lichtenstein and C. Jones, A self-organization theory of radical entrepreneurship. Best Papers Proceedings, National Academy of Management. OMT Division; CD Format (2004). 
Lichtenstein et al., 2006 • B. Lichtenstein, K. Dooley and T. Lumpkin, Measuring emergence in the dynamics of new venture creation, Journal of Business Venturing 21 (2006), pp. 153-175.

Lichtenstein et al., 2007 • B. Lichtenstein, M. Uhl-Bien, R. Marion, A. Seers and D. Orton, Complexity leadership theory: Explaining the interactive process of leading in complex adaptive systems, Emergence: Complexity and Organization 8 (4) (2007), pp. 2-12.

Maguire and McKelvey, 1999 - S. Maguire and B. McKelvey, Complexity and management: Moving from fad to firm foundations, Emergence 2 (1999), pp. 19-61.

Marion and Uhl-Bien, 2001 - R. Marion and M. Uhl-Bien, Leadership in complex organizations, The Leadership Quarterly 12 (4) (2001), pp. 389-418.

Marion and Uhl-Bien, 2008 • R. Marion and M. Uhl-Bien, Complexity theory and leadership: Social dynamics in the knowledge era, Information Age Publishing, Charlotte, NC (2008).

Maruyama, 1963 - M. Maruyama, The second cybernetics: Deviation-amplifying, mutual causal processes, American Scientist 51 (1963), pp. 164-179.

McKelvey, 2004a • B. McKelvey, Toward a complexity science of entrepreneurship, Journal of Business Venturing 19 (2004), pp. $313-342$.

McKelvey, 2004b - B. McKelvey, Toward a 0th law of thermodynamics: Order-creation complexity dynamics from physics \& biology to bioeconomics, Journal of Bioeconomics 6 (2004), pp. 65-96.

McKelvey and Lichtenstein, 2007 • B. McKelvey and B. Lichtenstein, Leadership in the four stages of emergence. In: J. Hazy, J. Goldstein and B. Lichtenstein, Editors, Complex systems leadership theory, ISCE Publishing, Boston, MA (2007), pp. 93-108.

Meyer et al., 2005 - A. D. Meyer, V. Gaba and K. A. Colwell, Organizing far from equilibrium: Nonlinear change in organizational fields, Organization Science 16 (2005), pp. 456-473.

Nicolis and Prigogine, 1989 • G. Nicolis and I. Prigogine, Exploring complexity, Freeman, San Francisco, CA (1989).

Olson and Eoyang, $2001 \cdot$ E. Olson and G. Eoyang, Facilitating organizational change, Jossey-Bass/Pfeffer, San Francisco, CA (2001).

Osborn and Hunt, 2007 • R. N. Osborn and J. Hunt, Leadership and the choice of order: Complexity and hierarchical perspectives near the edge of chaos, The Leadership Quarterly 18 (2007), pp. 319-340.

Osborn et al., 2002 • R. N. Osborn, J. G. Hunt and L. R. Jauch, Toward a contextual theory of leadership, The Leadership Quarterly 13 (2002), pp. 797-837.

Pascale et al., 2000 • R. T. Pascale, M. Millemann and L. Gioja, Surfing the edge of chaos, Three Rivers Press, New York (2000).

Plowman and Duchon, 2007 - D. A. Plowman and D. Duchon, Emergent leadership: Getting beyond heroes and scapegoats. In: J. Hazy, J. Goldstein and B. Lichtenstein, Editors, Complex systems leadership theory, ISCE Publishing Company, Boston, MA (2007), pp. 109-128.

Plowman and Duchon, 2008 - D. A. Plowman and D. Duchon, Dispelling the myths about leadership: From cybernetics to emergence. In: R. Marion, M. Uhl-Bien and P. Hanges, Editors, Complexity theory and leadership: Leadership dynamics in the knowledge era, Information Age Publishing Inc, Greenwich, CT. (2008), pp. 129-154.

Plowman et al., 2007 • D. A. Plowman, L. Baker, T. Beck, S. Silansky, M. Kulkarni and D. Travis, Radical change accidentally: The emergence and amplification of small change, Academy of Management Journal 50 (2007), pp. 515-543.

Plowman et al., 2007 • D. A. Plowman, S. Silansky, T. Beck, L. Baker, M. Kulkarni and D. Travis, The role of leadership in emergent, self-organization, The Leadership Quarterly 18 (2007), pp. 341-356.

Porter and McLaughlin, 2006 • L. Porter and G. McLaughlin, Leadership and the organizational context: Like the weather?, The Leadership Quarterly 17 (2006), pp. 559-576.

Prigogine, 1955 - I. Prigogine, An introduction to thermodynamics of irreversible processes, Thomas, Springfield, IL (1955).

Prigogine and Stengers, 1984 - I. Prigogine and I. Stengers, Order out of chaos: Man's new dialogue with nature, Bantam, New York (1984).

Rousseau and Fried, 2001 • D. Rousseau and Y. Fried, Location, location, location: Contextualizing organizational research, Journal of Organizational Behavior 22 (2001), pp. 1-13.

Sastry, 1997 - A. Sastry, Problems and paradoxes in a model of punctuated organizational change, Administrative Science Quarterly 42 (1997), pp. 237-275.

Schieve and Allen, 1982 - In: W. Schieve and P. Allen, Editors, Self-Organization and dissipative structures: Applications in the physical and social sciences, University of Texas Press, Austin, TX (1982).

Seers, 2005 - A. Seers, Creating leaderful organizations: How to bring out leadership in everyone, Leadership Quarterly 16 (2005), pp. $301-304$.

Senge et al., 2008 • P. Senge, B. Smith, N. Kruschwitz, J. Laur and S. Schley, The necessary revolution, Doubleday, N. Y. (2008).

Smith and Gemmill, 1991 • C. Smith and G. Gemmill, Self-organization in small groups: A study of group effectiveness within non-equilibrium conditions, Human Relations 44 (1991), pp. 697-716.

Swenson, 1989 - R. Swenson, Emergent attractor and the law of maximum entropy production: Foundations to a theory of general evolution, Systems Research 6 (3) (1989), pp. 187-197.

Swenson, 1992 - R. Swenson, Order, evolution, and natural law: Fundamental relations in complex system theory. In: C. Negoita, Editor, Cybernetics and applied systems, Marcel Dekker, Inc, New York (1992), pp. 125-147.

Uhl-Bien et al., 2007 - M. Uhl-Bien, R. Marion and B. McKelvey, Complexity leadership theory: Shifting leadership from the industrial age to the information era, The Leadership Quarterly 18 (2007), pp. 298-318.

Weick and Sutcliffe, 2005 - K. Weick, K. Sutcliffe and D. Obstfeld, Organizing and the process of sensemaking, Organization Science 16 (2005), pp. 409-421.

Wheelan and Johnston, 1996 S. A. Wheelan and F. Johnston, The role of informal member leaders in a system containing formal leaders, Small Group Research 27 (1996), pp. 33-55.

Yin, 2003 - R. Yin, Case study research: Design and methods, SAGE Publications, Newbury Park, CA (2003).

Yukl, 2006 • G. Yukl, Leadership in organizations, Pearson Education Inc, Upper Saddle, NJ (2006).

Yukl and Falbe, 1990 - G. Yukl and C. M. Falbe, Influence tactics in upward, downward, and lateral influence attempts, Journal of Applied Psychology 75 (1990), pp. 132-140.

Yukl and Chavez, 2002 - G. Yukl and C. Chavez, Influence tactics and leaders effectiveness. In: L. L. Neider and C. A. Schriesheim, Editors, Leadership, New Information Age Publishing, Greenwich. CT (2002), pp. 139-165. 